\title{
Masa-espektrometria bidezko prozedura analitiko berrien garapena Geokimika Isotopikoan eta haien aplikazioa presio altuko arroka metamorfikoen azterketan
}

(Development of new analytical procedures of isotope geochemistry by mass spectrometry and its application to the study of high-pressure metamorphic rocks)

Aratz Beranoaguirre ${ }^{1, *}$, Jose Ignacio Gil Ibarguchi ${ }^{2}$, Pablo Puelles Olarte ${ }^{3}$

${ }^{1}$ Instituto Geológico y Minero de España (IGME) eta Mineralogia eta Petrologia Saila, $\mathrm{UPV} / \mathrm{EHU}$

${ }^{2}$ Mineralogia eta Petrologia Saila, UPV/EHU

${ }^{3}$ Geodinamika Saila, UPV/EHU

* aratz.beranoaguirre@ehu.eus

DOI: $10.1387 /$ ekaia.17774

Laburpena: Geokimika Isotopikoak/Geokronologiak azken hamarkadetan izan duen bilakaerak hainbat teknika analitikoren hobekuntza eragin du, gerriko metamorfikoen tektonikaren gaineko informazioan iraultza eraginez. Euskal Herriko Unibertsitatea (UPV/EHU) berariazko tresneria analitikoaren jabe da, munduan gehien erabiltzen diren metodo geokronologikoen inplementazioa eta hobekuntza ahalbidetuz. Lan honetan, Rb-Sr eta Lu-Hf sistemak MC-ICP-MS bidez analizatzeko metodologia garatu da alde batetik, eta Hf-Hf eta U-Pb sistemak LA-ICP-MS bidez neurtzeko teknikak bestetik. Teknika horiek Iberiar mendigunearen ipar-mendebaldeko Malpica-Tui eta Cabo Ortegal Konplexu Aloktonoetako presio altuko arroka metamorfikoen dataziorako eta trazaketarako erabili dira.

Hitz gakoak: Geokronologia, masa-espektrometroa, arroka metamorfikoa.

Abstract: The development of Isotope Geochemistry/Geochronology has triggered many technical improvements in the past decades and has revolutionised the potential information available on the tectonics of metamorphic belts. The University of the Basque Country (UPV/EHU) has acquired the specific analytical equipment, which has 
allowed the implementation and improvement of several of the worldwide most used geochronological methods. In the present work, techniques for $\mathrm{Rb}-\mathrm{Sr}$ and $\mathrm{Lu}-\mathrm{Hf}$ analysis by MC-ICP-MS, and Hf-Hf and U-Pb analysis by LA-ICP-MS have been developed. These techniques have been employed to date and trace the origin of high-pressure rocks from the Malpica-Tui and Cabo Ortegal Allochthonous Complexes of the NW Iberian Massif.

Keywords: Geochronology, mass spectrometer, metamorphic rock.

\section{SARRERA}

«Zein da Lurraren adina?» Galdera horri erantzun bat eman nahiak gizakiaren pentsaeran eragin ikaragarria izan du mendeetan zehar. Geologiaren sorrerarekin kontu hori objektiboagoa bilakatu zen; zientzialariek adin erlatiboetan oinarritutako denbora-eskala geologikoa garatzen hasi baitziren. Erradioaktibitatearen aurkikuntzak mugarri garrantzitsua ezarri zuen arroken datazioari dagokionez, berau erloju moduan erabil zitekeela ohartu baitziren. 1907an lehen datazio erradiometrikoak argitaratu ziren [1], Geokronologia, Lurreko materialen adina neurtzen duen lur-zientzien adarra, jaioaz.

Azken hamarkadetan Geokimika Isotopikoan zein Geokronologian egin diren hobekuntza instrumentalek aukera sorta zabala sortu dute, arroka metamorfikoetan lor daitekeen informazioa ikaragarri zabalduz. Horrela, klasikoak ziren geokronometroei, U-Pb edo Rb-Sr kasu, Lu-Hf edo Re-Os bezalako sistemen analisiak gehitu zaizkie. Hobekuntza horiek masa espektrometro berrien merkaturatzearekin batera gertatu dira. XX. mendean ionizazio termikoan oinarritutako TIMS instrumentuekin egiten ziren analisirik gehienak, 80. hamarkadan induktiboki akoplatutako plasma iturridun masa-espektrometroak (ICP-MS) agertu ziren arte. 90. hamarkadaren erdialdera, ICP tresnak masa-iragazki magnetiko edo/eta detektagailu anitzeko sistema batez hornitu ziren, eta detektagailu anitzeko induktiboki akoplatutako plasma iturridun masa-espektrometroak (MC-ICP-MS) eta induktiboki akoplatutako plasma iturridun masa-espektrometro kuadrupolarrak (Q-ICPMS) agertu ziren [2].

Euskal Herriko Unibertsitatea (UPV/EHU) aipatutako ekipoen jabe da, eta horien erabileran aurrerapausoak eman nahian garatu diren teknika ezberdinak aurkezten dira artikulu honetan.

\section{TRESNERIA}

Lana bi masa-espektrometro ezberdinen bidez egindako analisietan oinarritzen da: alde batetik, MC-ICP-MSa, zeinetan laginak solido- zein likido-egoeran analizatu diren, eta bestetik, Q-ICP-MSa, zeinetan solido-egoe- 
Masa-espektrometria bidezko prozedura analitiko berrien garapena

Geokimika Isotopikoan eta haien aplikazioa presio altuko arroka metamorfikoen azterketan

ran sartutako laginak neurtu diren, horretarako Nd:YAG solido-egoerako laser ablazio-sistema erabiliz. Ekipoak Geokronologia eta Geokimika Isotopikoaren Zerbitzuari (IBERCRON) dagozkio, UPV/EHUren Ikerkuntzarako Zerbitzu Orokorren (SGIker) barruan.

\section{GARATUTAKO TEKNIKAK}

\subsection{Rb-Sr sistema}

$\mathrm{Rb}-\mathrm{Sr}$ bikotea prozesu geokimikoetako isotopo trazatzaile bezala erabil daiteke, baita geokronometro bezala ere, ${ }^{87} \mathrm{Rb}$-tik ${ }^{87} \mathrm{Sr}$-rako desintegrazio erradioaktiboa dela eta [3]. Rubidioak potasioaren antzeko ezaugarriak ditu eta potasiodun mineraletan, miketan edo feldespato potasikoan kasu, $\mathrm{K}^{+}$ordezkatzeko ahalmena dauka. Estrontzioak, berriz, kaltzioa ordezkatzeko joera izaten du. Ezaugarrien ezberdintasuna dela eta, elementu biak frakzionatu egiten dira eta $\mathrm{Rb}$-Sr arrazoi ezberdinak dituzten mineralak kristaltzen dira. Ondorioz, isokrona metodoaren bidez datazio erradiometrikoak kalkulatzeko aukera ematen dute.

Isotopoen arrazoien neurketa egin aurretik, lagina era egokian prestatu behar da, lagina azido ezberdinekin disolbatuz eta ${ }^{87} \mathrm{Rb} /{ }^{86} \mathrm{Sr}$ arrazoia ahalik eta zehatzen eta zuzenen neurtzeko ezinbestekoa den trazatzailea, isotopo jakin batean aberastuta dagoen disoluzioa, gehituz. Ondoren, intereseko elementuak gainerako elementuetatik isolatzea beharrezkoa da, masa/karga $=87$ an gerta daitekeen interferentzia isobarikoa ekiditeko. Laginak bi banaketa-prozesu jasaten ditu, erauzte eta katioi-truke kromatografian oinarritutako erretxina ezberdinekin [4]. Erretxina eta azido ezberdinen aurrean duten portaera ezberdinak $\mathrm{Rb}$-aren eta $\mathrm{Sr}$-aren isolamendua ahalbidetzen du. Elementuak isolaturik daudenean, MC-ICP-MSan neurtzen dira.

Metodoa balioztatzeko, hau da, laginaren disoluzio-prozesua, banaketa kimikoa eta neurketak egokiak direla baieztatzeko, ezagunak diren nazioarteko erreferentziazko estandarren analisiak egiten dira. 1. irudian, erreferentziazko material desberdinetan lortutako ${ }^{87} \mathrm{Sr} /{ }^{86} \mathrm{Sr}$ arrazoiaren, Sr eta $\mathrm{Rb}$ kontzentrazioen balioen konparaketa egiten da. X ardatzean lan honetan aurkeztutako metodoaren bitartez lortutako balioak azaltzen dira, eta Y ardatzean, berriz, bibliografiako balioak. Ikus daitekeen moduan, datuen arteko korrelazioa ezin hobea da.

\subsection{Lu-Hf sistema}

Lu-Hf bikotea ere isotopo trazatzaile eta geokronometro bezala erabiltzen da, ${ }^{176} \mathrm{Lu}-a k{ }^{176} \mathrm{Hf}$-rako desintegrazioa erakusten baitu [5]. Prozesu geokimiko askok bi elementu horien banaketa handia eragiten dute, gor- 
putz geologiko beraren barnean ezaugarri geokimiko ezberdinak dituzten erreserborio bereizgarriak ahalbidetuz. Zehazki, Lu-a erraz sartzen da granate, apatito edo lawsonitaren kristal-egituraren barruan, Hf-a mineral osagarri jakin batzuekin soilik (zirkoia, rutiloa) bateragarria den bitartean.
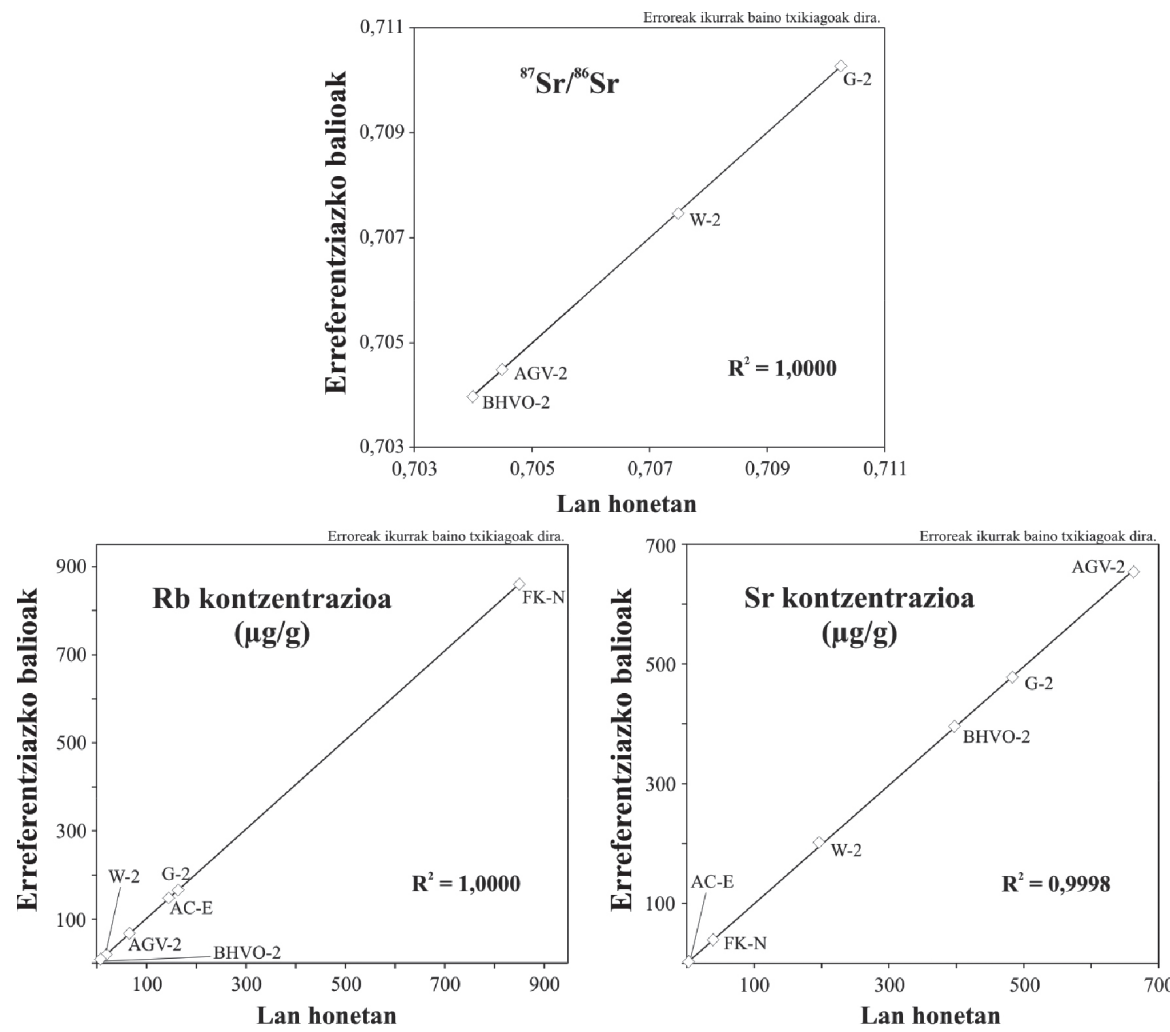

1. irudia. Erreferentziazko material desberdinetan, gure laborategietan lortutako balioen eta bibliografiako balioen arteko konparaketa grafikoa, $\mathrm{Rb}-\mathrm{Sr}$ sistemari dagokionez.

Aipatutako mineral osagarriak Hf-aren erreserborio nagusiak dira; beraz, horiek disolbatu ala ez, lortuko den emaitzaren esanahia ezberdina izan daiteke. Horregatik, laginaren disoluzio-prozesua helburuaren araberakoa da. Mineral horiek disolbatzeko fusio bidezko erasoa egin da, laginean dagoen Hf guztia disoluziora pasa dela ziurtatuz. Helburua arrokaren zati jakin baten Hf konposizioa aztertzea bada (banatutako mineralena), azidoen bidezko erasoa egokiagotzat jo da, erregogorrak diren mineralak disolbatu gabe uztea ahalbidetzen baitu. Kasu horretan ere, ezinbestekoa da trazatzaile baten gehitzea. 
${ }^{176} \mathrm{Yb},{ }^{176} \mathrm{Lu}$ eta ${ }^{176} \mathrm{Hf}$ isotopoek elkarren gaineko interferentziak sortzen dituztenez, beharrezkoa da Yb-a, Lu-a eta Hf-a isolatzea MC-ICPMSan analisiak egin aurretik. Banaketa aurrera eramateko, katioi-truke eta erauzte-kromatografian oinarritutako erretxinak erabiltzen dira.

Lehenago egin den bezala, metodoa balioztatzeko ezagunak diren erreferentziazko estandarren analisiak egin dira (2. irudia), datuen arteko korrelazioa ona izanik berriz ere.
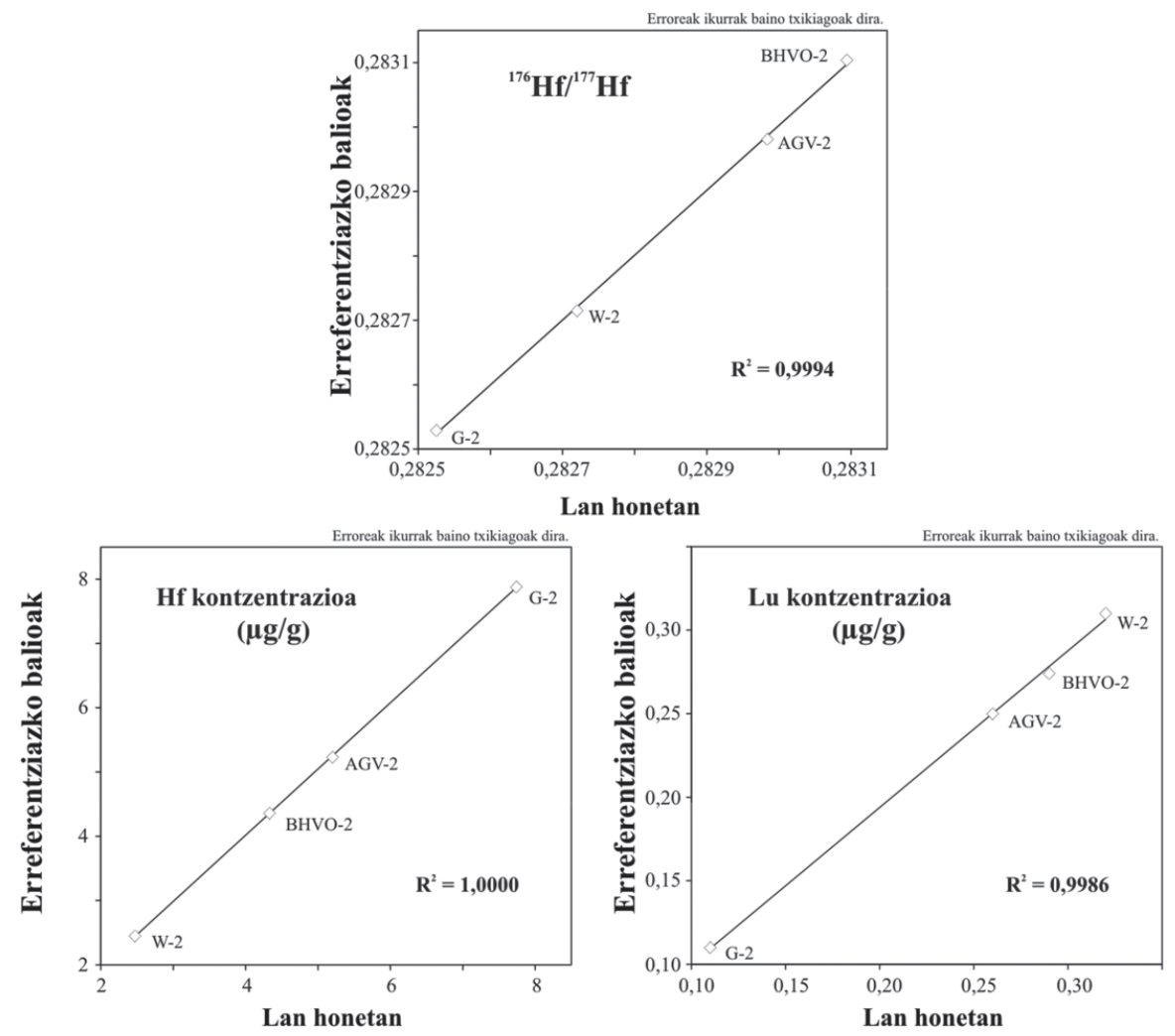

2. irudia. Erreferentziazko material desberdinetan, UPV/EHUn lortutako balioen eta bibliografiako balioen arteko konparaketa grafikoa, Lu-Hf sistemari dagokionez. Erroreak ikurrak baino txikiagoak dira.

\subsection{U-Th-Pb sistema}

Geologian, gehien erabiltzen den geokronometroa U-Th-Pb sistema da, batez ere zirkoien dataziorako. Sistema horretan 3 desintegrazio-sistema bereizten dira, uraniotik berunerako desintegrazio bi eta toriotik berunerako 
beste desintegrazio bat [6]. U-a eta Th-a elementu ez-bateragarriak dira eta zirkoia edo monazita bezalako mineral osagarrietan kontzentratzeko joera dute, berunak ez bezala. Horrek hiru elementuen banaketa dakar mineral ezberdinetan, $\mathrm{U} / \mathrm{Pb}$ eta $\mathrm{Th} / \mathrm{Pb}$ arrazoi ezberdinak emanez eta adin erradiometrikoen kalkuluak ahalbidetuz.

$\mathrm{U}-\mathrm{Th}-\mathrm{Pb}$ sistemaren analisi isotopikoak Q-ICP-MSari akoplatutako laser ablazio-sistemaren bidez gauzatzen dira, geologian erabiltzen diren xafla petrografikoan zuzenean.

Aurreko tekniketan ez bezala, laser-ablazio bidezko analisietan ez dago elementu ezberdinen banaketarik eta horrek hainbat arazo eragin ditzake. Analisi bakoitzeko datuak gordinean aztertzen dira, analisiak asalda ditzakeen zerbait dagoen ikusteko, besteak beste, inklusioak, hausturak edo adin desberdinetako domeinuen nahasketa. Horrelako teknikekin egindako analisiek zatikapen eta jito instrumental nabariak dituzte, eta horiek zuzentzeko nazioarteko estandarrak laginekin tartekatzen dira. Balioztapenerako erabiltzen diren zirkoietan lortutako emaitzak bat datoz argitaratutako datuekin (3. irudia).
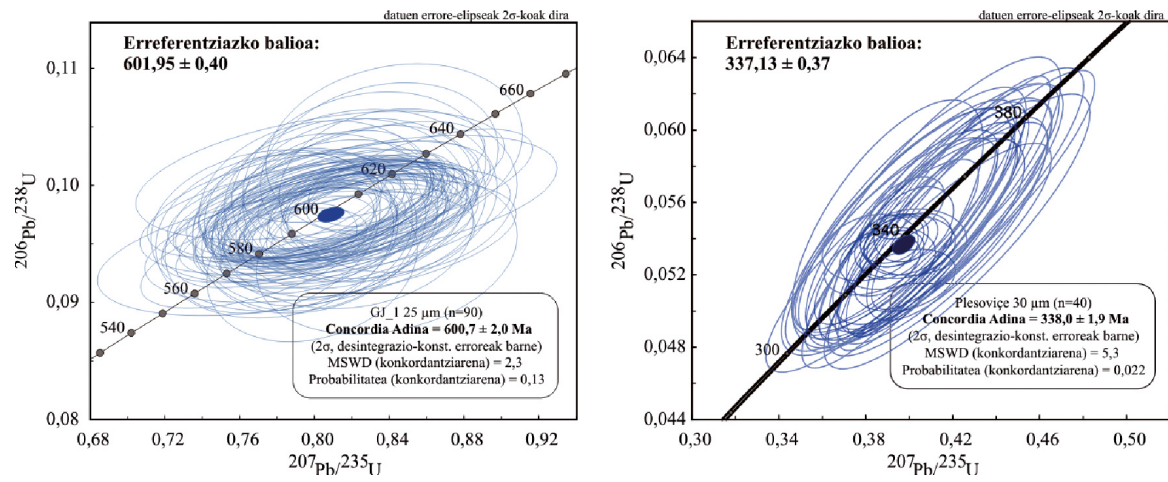

3. irudia. GJ-1 eta Plešovice zirkoi estandarretan egindako U-Pb analisien Concordia motako diagramak.

\subsection{Hf-Hf sistema}

Lu-Hf sistemaren ezaugarriak direla eta, Hf-aren konposizio isotopikoa mineral jakin batzuen trazatzaile gisa erabiltzeko aukera ere badago. Zirkonioaren jokaera geokimiko antzekoa daukanez, Hf-ak zirkoia bezalako mineraletarako bateragarritasun handia dauka eta horien kristal-egituran harrapatuta geratzen da, Lu-a ez bezala. Ondorioz, ${ }^{176} \mathrm{Hf}$ erradiogenikoagatik Hf-aren konposizio isotopikoan gerta daitezkeen aldaketak baztergarriak 
Masa-espektrometria bidezko prozedura analitiko berrien garapena Geokimika Isotopikoan eta haien aplikazioa presio altuko arroka metamorfikoen azterketan

dira, hau da, zirkoiak kristalizatu ziren jatorriko ${ }^{176} \mathrm{Hf} /{ }^{177} \mathrm{Hf}$ arrazoiak mantentzen ditu. Hori benetan interesgarria da Hf konposizio isotopiko ezberdinetan (baldintza geologiko ezberdinetan) hazitako kristal baten domeinu ezberdinen azterketa ahalbidetzen duelako.

Analisi horiek ere laser-ablazio bidez egiten dira, baina kasu honetan MC-ICP-MSaren laguntzarekin eta prozeduraren balioztapenerako gehien erabiltzen diren lau zirkoi estandarrak analizatu dira (1. taula). Zirkoi horiek ${ }^{176} \mathrm{Hf} /{ }^{177} \mathrm{Hf}$ arrazoi eta Yb kontzentrazio sorta zabala hartzen dituzte baitan, azkena zuzenketak era egokian egiten direla baieztatzeko.

1. taula. Zirkoi estandarren ${ }^{176} \mathrm{Hf} /{ }^{177} \mathrm{Hf}$ erreferentziazko balioak, disoluzio eta laser-ablazio bidezko analisietarako, eta lan honetan lortutako emaitzak. Erroreak $2 \sigma-k o a k$ dira; «n» analisi kopurua da.

\begin{tabular}{l|cc|cc}
\hline \multirow{2}{*}{} & \multicolumn{2}{|c|}{ Onartutako Balioak } & \multicolumn{2}{c}{ Lan honetan } \\
\cline { 2 - 5 } & Disoluzioa & Laser Ablazioa & Emaitza & $\mathrm{n}$ \\
\hline GJ-1 & $0,282000 \pm 5$ & $0,282015 \pm 29$ & $0,282003 \pm 17$ & 44 \\
M1500 & $0,282306 \pm 8$ & $0,282299 \pm 26$ & $0,282288 \pm 15$ & 10 \\
Mudtank & $0,282507 \pm 6$ & $0,282522 \pm 19$ & $0,282508 \pm 13$ & 20 \\
Plešovice & $0,282484 \pm 8$ & $0,282486 \pm 28$ & $0,282472 \pm 12$ & 20 \\
\hline
\end{tabular}

\section{APLIKAZIOA}

\subsection{Eskualde geologikoa}

Aztertutako laginak Iberiar mendigunearen ipar-mendebaldeko sekzioan bildu dira, eta Europako Gerriko Variskarraren azaleramendu mendebaldekoenei dagozkie. Gerriko Variskarra Laurasia eta Gondwana kontinenteen arteko talkaren emaitza da Paleozoiko berantiarrean, Pangea azken superkontinentea eratu aurretik. Iberiar penintsularen NWean, arroka mafiko eta ultramafiko ugari dituzten 5 konplexu metamorfiko aurki daitezke: Malpica-Tui, Cabo Ortegal, Ordenes, Bragança eta Morais. Aztertu diren arrokak lehen biei dagozkie. Konplexu horiek subdukzio maila ezberdinak jasandako litosfera ozeaniko edo/eta kontinental zatiak dira, Orogenia Variskarrean Gondwanaren ertzaren gaineko obdukzioa pairatu zutenak [7]. Konplexuen barnean 3 unitate estruktural nagusi bereiz daitezke: tenperatura baxu-ertaina/presio altua duen Behe Aloktonoa azpialdean, Konplexu Ofiolitikoa erdian eta tenperatura altua/presio altua duten arrokak dituen Goi Aloktonoa. 
Cabo Ortegal Konplexua batez ere Konplexu Ofiolitikoari eta Goi Aloktonoari dagozkion teilakatutako mantu unitateez osatzen da. Bertan, jatorri ozeanikodun presio altuko arrokak azaleratzen dira, besteak beste, presio altuko granulitak, eklogitak, metaperidotitak, orto- eta para-gneisak, metagabroak eta metaserpentinitak [8]. Malpica-Tui Konplexua Behe Aloktonoko unitatez osatzen da batez ere, eta arrokek dituzten ezaugarriek jatorri kontinental eta kontinental/ozeaniko trantsizionala iradokitzen dute. Konplexu horretan, heterogeneoki deformatutako arroka sedimentario eta igneo multzoa azaleratzen da, hala nola, eskisto berdeak, anfibolitak, eklogitak, ortogneisak eta arroka metasedimentarioak [9].

\subsection{Laginen deskribapena eta emaitzak}

Malpica-Tui Konplexuan bi eklogita aztertu dira: eklogita arrunta eta muskobitadun eklogita. Arroka biak erlazionatuta agertzen dira azaleramenduetan eta kimikoki ere antzeko konposizioa daukate, eboluzio magmatiko berberaren produktuak direla iradokiz. Kalkulatutako presio- eta tenperatura-baldintzak $2,6 \mathrm{GPa}$ eta $610^{\circ} \mathrm{C}$-ko balio maximoetaraino heltzen dira [9]. Eklogita arruntek pikor tamaina fin-ertaina dute, eta orekan dagoen mineral-elkartea klinopiroxenoz eta granatez eratzen da batez ere, kuartzo, rutilo, zoisita eta zianita kantitate txikiekin. Anfibolak mineral sekundario moduan agertzen dira. Muskobitadun eklogitek pikor tamaina finagoa erakusten dute, eta erretrogresio arinagoa jasan dute. Orekan dagoen mineral-elkartea heterogeneoagoa da eta ondoko mineralez eratzen da: klinopiroxenoa, granatea, kuartzoa, anfibola, muskobita eta zoisita; rutilo, apatito eta zirkoi gutxi batzuekin.

$\mathrm{Rb}-\mathrm{Sr}$ eta Lu-Hf geokronologia aztertzeko, banatutako mineralen eta arroka osoaren analisiak egin dira, $\mathrm{Rb}-\mathrm{Sr}$ sistemarako muskobitak eta LuHf sistemarako granate eta piroxenoak banatu direlarik. Emaitzak 4. irudian ikus daitezke. Lu/Hf adinak, $375 \mathrm{Ma}$ inguru, presio altuko metamorfismoarekin, subdukzioarekin, lotu ohi dira eta $\mathrm{Rb} / \mathrm{Sr}$ adinak, $350 \mathrm{Ma}$, exhumazio edo obdukzioarekin. Muskobitadun eklogitako analisiek ez dute isokrona on bat irudikatzen, eta kasu horretan, arroka osoaren analisia gaitzetsi egin da; petrografikoki, piroxeno eta granatearen artean oreka dagoela ziurtatu baitaiteke.

Cabo Ortegal Konplexuan datatu den migmatita Goi Aloktonoari dagokio. Landan erraz identifikatzen diren arrokak dira fusio partziala jasan dutelako. Orekan dagoen mineral-elkartea ondoko mineralek osatzen dute: granatea, muskobita, kuartzoa, feldespato potasikoa, plagioklasa eta zoisita, eta lagin jakin batzuetan baita biotita eta zianita ere. Kalkulatutako presioeta tenperatura-baldintzak $1,8 \mathrm{GPa}$ eta $800^{\circ} \mathrm{C}$-koak dira [10].

Dena dela, arrokaren ezaugarririk interesgarriena zirkoien ugaritasuna da. Mikroskopio elektronikoaren bidez egindako argazkietan bi motatako 

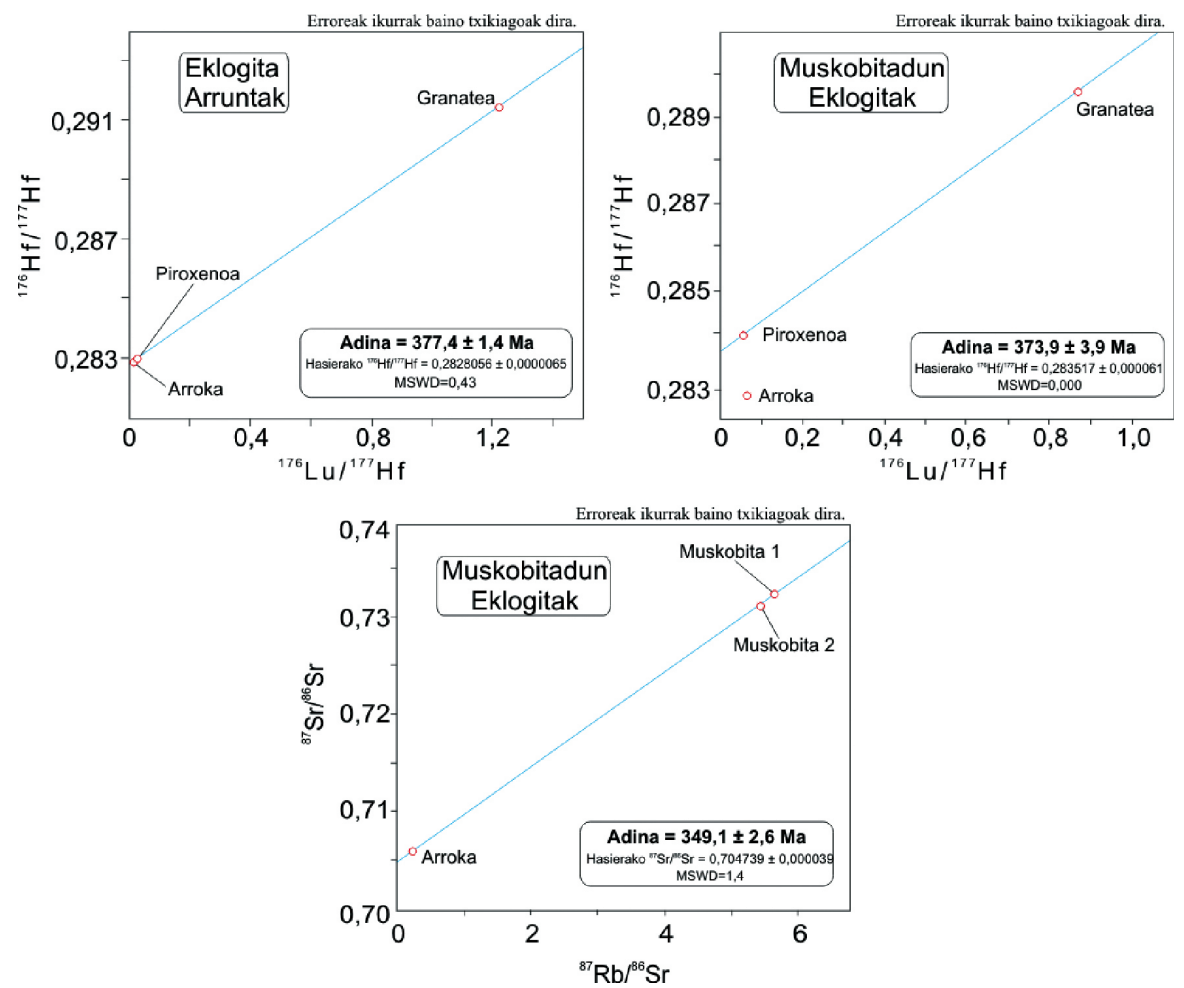

4. irudia. Malpica-Tui Konplexuko laginetan lortutako Lu-Hf eta Rb-Sr adinak.

zirkoiak ezberdindu daitezke: zonazioa erakusten duten zirkoi handiak (400 $\mu$ m-rainokoak) eta zirkoi txiki homogeneoak $(25-30 \mu \mathrm{m})$. Zirkoi horiek U-Pb eta Hf-Hf analisiak egiteko erabili dira.

$\mathrm{U}-\mathrm{Pb}$ sistemarekin lortu diren adinak 5a. irudian ikus daitezke. Adinik zaharrenak, $460 \mathrm{Ma}$ eta $480 \mathrm{Ma}$, zirkoien nukleoetan lortu dira. $390 \mathrm{Ma}$ inguruko adinak zirkoien ertzei dagozkie (5b. irudia); adinik gazteenak, $357 \mathrm{Ma}$ (5d. irudia), zirkoi txiki homogeneoetan lortu direlarik. 420-440 Ma-ko eremua adin diferenteetako domeinuen nahasketa da.

Hf-Hf analisiei dagokienez, zirkoi handien analisiak baino ez dira egin, zirkoi txikiak ez direlako teknikak behar duen gutxiengo tamainara iristen. 6. irudian ikus daitekeen moduan, bi multzo bereiz daitezke. 

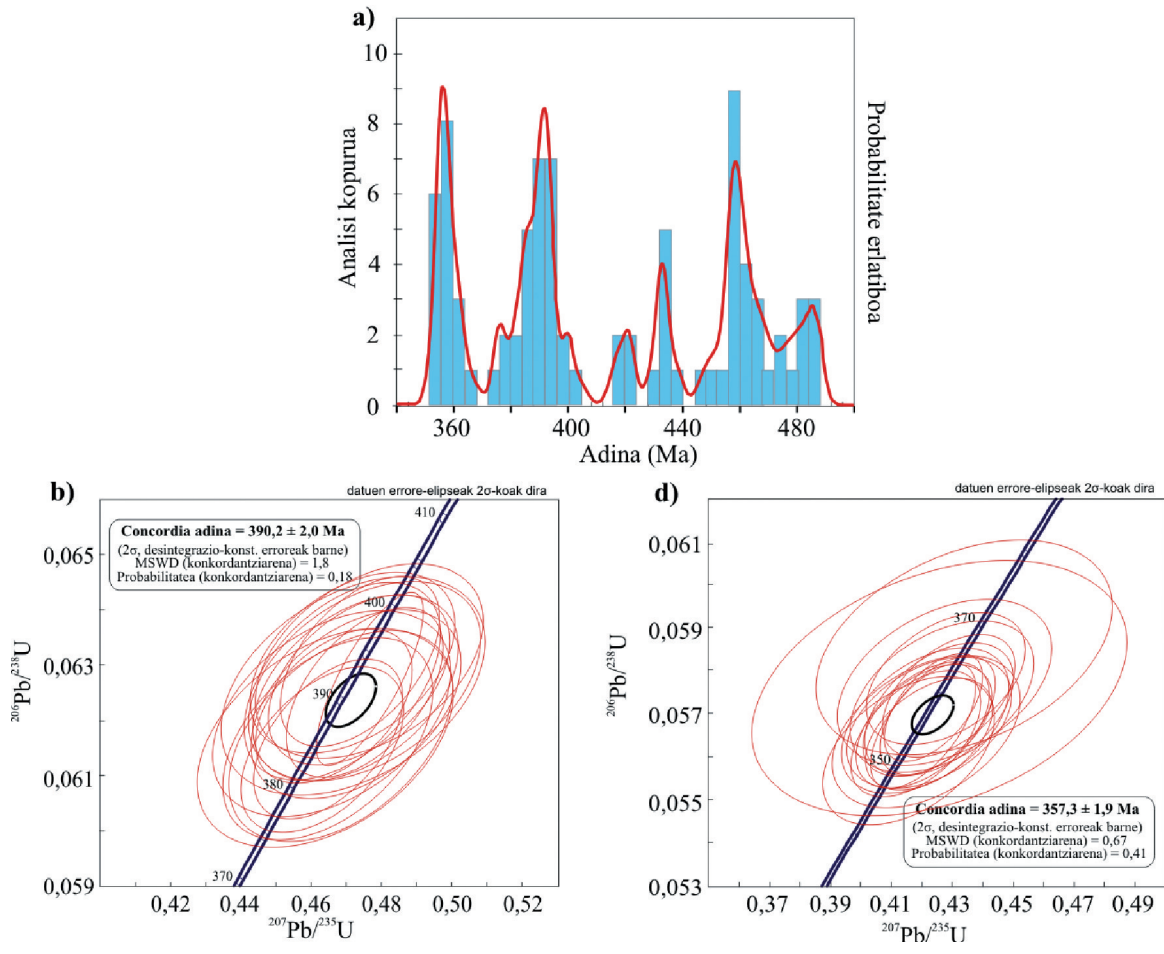

5. irudia. Cabo Ortegaleko migmatitaren datazioak. a) U-Pb analisien histograma; b) zirkoi handien ertzetako analisien U-Pb Concordia diagrama; d) zirkoi txiki homogeneoen analisien U-Pb Concordia diagrama.

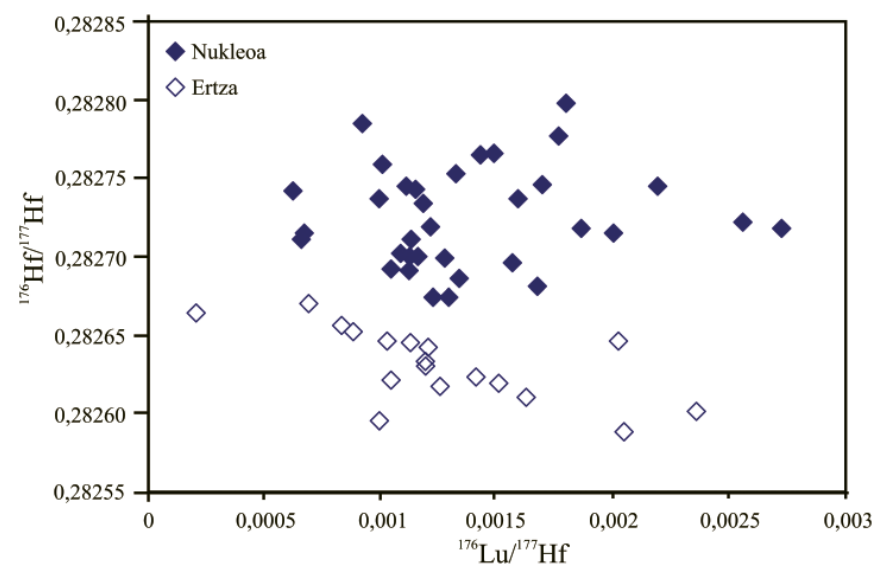

6. irudia. Cabo Ortegaleko zirkoietan analizatutako ${ }^{176} \mathrm{Hf} /{ }^{177} \mathrm{Hf}-{ }^{176} \mathrm{Lu} /{ }^{177} \mathrm{Hf}$ grafikoa. 
Masa-espektrometria bidezko prozedura analitiko berrien garapena

Geokimika Isotopikoan eta haien aplikazioa presio altuko arroka

metamorfikoen azterketan

\subsection{Interpretazioa}

Aurkeztutako datuek, behaketa petrografikoen laguntzarekin betiere, Konplexu Aloktonoetako arroka metamorfikoak Devoniarrean gertatutako subdukzio-exhumazio ziklo bakar bati lotuta daudela iradokitzen dute, kontinenteen arteko talkarekin zigilaturik geratzen dena.

Protolitoen adin Kanbro-Ordoviziarra ondo finkatuta zegoen lehendik ere, eta migmatitetan lortutako adinak arku bolkaniko baten lurrazal sakoneko galdatuen sorrera moduan interpretatzen dira. Arroka ezberdinetan eta teknika ezberdinen bidez lortutako adin erradiometrikoek sendo iradokitzen dute orain dela 390 Ma presio altuko metamorfismoa eragin zuen subdukzio-prozesu bat gertatu zela Iberiar penintsulako NWko Konplexuetako Goi Aloktonoan, Cabo Ortegalen. Lurperatze sakonenean arroka batzuk urtzera heldu ziren, eta Hf isotopoen azterketatik, sistema ireki egin zela ondoriozta daiteke; hau da, inguruko unitateekin elementu-trukaketa egon zela, sistema itxi batean zirkoien ertzetako Hf arrazoiak nukleoenetakoak baino handiagoak beharko bailukete. Behe Aloktonoetako subdukzioa orain dela 375 Ma gertatu zen, Reiko Ozeanoaren zabalera txikia zela iradokiz.

Muskobitaren Rb-Sr geokronometroaren ezaugarriak kontuan hartuta, Lu-Hf adinetik gertuago legokeen $\mathrm{Rb} / \mathrm{Sr}$ adina espero zitekeen, are gehiago landan ikus daitezkeen ezaugarri estrukturalekin. Lortutako adinak bestelako interpretazio bat egitera garamatza, $\mathrm{Rb}-\mathrm{Sr}$ datuak zirkoi txikietan lortutako emaitzekin gutxi gorabehera bat datozela kontuan hartuta gainera. Lortutako datu horiek subdukzio-prozesuan askatutako fluidoen aktibitate garrantzitsu batekin lot daitezke, horrelako testuinguru batean ohikoa dena bestalde. Fluido horien aktibitatea da, hain zuzen ere, Rb-Sr sistemaren irekiera eta zirkoi txikien kristaltzea ekarriko lukeena.

Fazie, litologia eta unitate multzo guztiak Reiko Ozeanoaren itxieragatik zigilatuta geratuko lirateke; azkenik, Karbonifero garaian, kontinenteen arteko talka, Gondwanaren gaineko zamalkadura eta granitoen intrusioa gertatu zen [11].

\section{ONDORIOAK}

Azken urteetan Geokronologian eman diren aurrerapenak orain dela gutxi arte sinestezinak diren maila analitikora heldu dira. Lan honetan, UPV/EHUko laborategietan modu egokian garatu diren lau metodologia berri aurrera eraman dira, teknika analitiko eta sistema isotopiko bakoitzak dituen arazo eta berezitasunak arrakastarekin ebatziz. Horrela, Rb-Sr, Lu$\mathrm{Hf}, \mathrm{U}-\mathrm{Pb}$ eta $\mathrm{Hf}-\mathrm{Hf}$ analisiak egiteko aukera zientzia-komunitatearen esku geratzen da. 
Teknika horien azken helburua prozesu geologikoak interpretatu ahal izateko behar diren datu geokimiko eta geokronologikoak eskuratzea da. Kasu honetan Iberiar penintsulako Konplexu Aloktonoetako laginak aztertu dira, ondokoa ebatziz: Konplexuak Devoniarrean gertatutako subdukzio-exhumazio ziklo baten produktu dira. Goi Aloktonoen lurperatze maximoan sistema ireki egin zen, baita partzialki urtu ere. Behe Aloktonoaren subdukzioa goi-unitateena baino 15-20 Ma beranduago gertatu zen. Rb-Sr datuek eta zirkoi berrien kristaltzeak fluidoen aktibitate garrantzitsua iradokitzen dute exhumazio-prozesuan zehar.

\section{ESKER ONAK}

Artikulu hau UPV/EHUk finantzatutako GIU09/61 proiektuari eta Espainiako Gobernuak finantzatutako CGL2008-01130/BTE proiektuari esker burutu da. Aratz Beranoaguirre egileak Espainiako Gobernuaren FPU AP2008-00746 bekaren diru-laguntza ere jaso du.

\section{BIBLIOGRAFIA}

[1] BOLTWOOD, B., 1907. «The Ultimate Disintegration Products of the Radio-active Elements. Part II. The disintegration products of uranium». American Journal of Science, 23, 77-88.

[2] SCHALTEGGER, U., SCHMITT, A.K. eta HORSTWOOD, M.S.A. 2015. «U-Th-Pb zircon geochronology by ID-TIMS, SIMS, and laser ablation ICPMS: Recipes, interpretations, and opportunities». Chemical Geology, 402, 89-110.

[3] HAHN, O., STRAMANN, H., MATTAUCH, J. eta EWALD, H. 1943. «Geologische Altersbestimmungen nach der Strontiummethode». Chemiker Zeitung, 67, 55-56.

[4] PIN, C. eta SANTOS ZALDUEGUI, J.F. 1997. «Sequential separation of light rare-earth elements, thorium and uranium by miniaturized extraction chromatography: Application to isotopic analyses of silicate rocks». Analytica Chimica Acta, 339, 79-89.

[5] PATCHETT, P.J. eta TATSUMOTO, M. 1980. «A routine high-precision method for Lu-Hf isotope geochemistry and chronology». Contributions to Mineralogy and Petrology, 75, 263-267.

[6] STEIGER, R.H. eta JÄGER, E. 1977. «Subcommission on geochronology: convention on the use of decay constants in geo- and cosmochronology». Earth and Planetary Science Letters, 36, 359-362.

[7] RIES, A. eta SHACKLETON, R.M. 1971. «Catazonal complexes of northwestern Spain and north Portugal; remmants of a hercynian thrust plate». Nature, 234, 65-69. 
Masa-espektrometria bidezko prozedura analitiko berrien garapena

Geokimika Isotopikoan eta haien aplikazioa presio altuko arroka metamorfikoen azterketan

[8] GIL IBARGUCHI, J.I., ÁBALOS, B., AZCÁRRAGA, J., MENDIA, M.S. eta PUELLES, P., 2000. A petrological and structural excursion through the high-grade/high-pressure allochthonous units of the Cabo Ortegal Complex (NW Spain). Basement Tectonics 15, Mid-Conference Field Trip Guide, Int. Basement Tectonics Assoc., A Coruña.

[9] RODRÍGUEZ, J. 2005. Recristalización y deformación de litologías supracorticales sometidas a metamorfismo de alta presión (Complejo de MalpicaTui, NO del Macizo Ibérico). Nova Terra 29, Universidade da Coruña.

[10] BERANOAGUIRRE, A. 2010. Petrology of subduction-related, high-pressure migmatites within granulites of the Cabo Ortegal complex (NW Iberian Massif). MsC thesis, Universidad de Granada.

[11] STAMPFLI, G.M., HOCHARD, C., VÉRARD, C., WILHEM, C., eta VON RAUMER, J., 2013. «The geodynamics of Pangea formation». Tectonophysics, 593, 1-19. 